\title{
PEKTIN JERUK BALI (Citrus maxima, L) DALAM FORMULASI SIRUP KERING BUAH MENGKUDU
}

\section{CITRUS PECTIN (Citrus maxima, L) IN MORINDA DRY SYRUP FORMULATION}

\author{
Heru Agus Cahyanto \\ Balai Riset dan Standardisasi Industri Pontianak \\ Jl. Budi Utomo 41 Pontianak \\ email : heru-a@kemenperin.go.id
}

Diterima : 21-02-2017 Direvisi : 28-04-2017_Disetujui : 19-05-2017

\begin{abstract}
ABSTRAK
Telah dilakukan penelitian penggunaan pektin jeruk bali sebagai bahan penstabil dalam formula sirup kering buah mengkudu. Sirup kering buah mengkudu menggunakan bahan aktif buah mengkudu dan diformulasikan dalam sediaan sirup kering dengan penambahan bahan penstabil berupa pektin dari kulit jeruk bali. Penelitian ini dilakukan dengan membuat variasi jumlah pektin yaitu $0 ; 0,5 ; 1$ dan $1,5 \%$ pada formula sirup kering, sementara jumlah sakarosa dalam formula adalah tetap sebesar $20 \%$. Uji fisik terhadap produk sirup kering meliputi: kestabilan $\mathrm{pH}$, viskositas, endapan, angka lempeng total, angka kapang dan khamir selama 7 hari. Hasil uji menunjukkan penambahan pektin berpengaruh terhadap kastabilan sirup kering buah mengkudu. Formula sirup kering dengan penambahan pektin $0,5 \%$ memiliki pH 4.57, viskositas 540 serta nilai ALT jauh dibawah batas $\leq 10^{6}$ $\mathrm{kol} / \mathrm{gr}$ dan $\mathrm{AKK} \leq 10^{4} \mathrm{kol} / \mathrm{gr}$.
\end{abstract}

Kata kunci : pektin, sirup kering, mengkudu

\section{ABSTRACT}

The research of pectin as a stabilizer in Morinda dry syrup had been carried out. Morinda dry syrup using morinda citrifolia fruit as active ingredients and formulated in dry syrup with the addition of a pectin as stabilizer from Citrus maxima $L$. This research was done by varying of pectin amount ie 0; 0,$5 ; 1$ and $1.5 \%$ in dry syrup formulas, while the amount of saccharose in the formula is fixed at 20\%. Physical tests carried out on dried syrup products include: pH stability, viscosity, precipitate, total plate number, yeast figures for 7 days. The results showed that the addition of pectin has an effect on Morinda dry syrup. The dry syrup formula with $0.5 \%$ pectin addition has a $\mathrm{pH} 4.57$, the viscosity 540 and the $A L T$ value below the limit $\leq 10^{6} \mathrm{kol} / \mathrm{gr}$ and $A K K \leq 10^{4} \mathrm{kol} / \mathrm{gr}$.

Keywords : pectin, dry syrup, morinda citrifolia

\section{PENDAHULUAN}

$\mathrm{K}$ alimantan Barat memiliki berbagai potensi buah-buahan untuk dikembangkan, salah satunya adalah tanamanan buah jeruk bali. Tanaman jeruk bali tumbuh subur di lahan gambut namun kurang diberdayakan oleh masyarakat. Pengelolaan tanaman ini biasanya disesuaikan dengan kebutuhan akan jeruk bali terutama perayaan keagamaan.

Jeruk bali mengandung berbagai komponen nutrisi. Selain sumber vitamin $\mathrm{C}$, jeruk bali juga memiliki kandungan pektin di dalam albedonya. Selama ini kulit jeruk bali hanya dibuang sebagai sampah, tidak termanfaatkan. Menurut penelitian kandungan pektin jeruk bali berkisar antara $16,68 \%$ sampai $21,95 \%$ (Wang et al, 2014).

Pektin merupakan komponen utama yang terdapat dalam dinding sel primer dan lamela tengah antar sel tanaman mencakup polisakarida berupa asam galakturonat. Poliskarida utama yang menyusun polimer pektin adalah 
homogalakturonan, rhamnogalakturonan-I, dan rhamnogalakturonan-II (Willats et al, 2001). Struktur pektin memiliki daerah yang disebut smooth region dan hairy region. Hairy region lebih fleksibel karena memiliki rantai cabang arabinogalaktan (Yadav, 2008).

Kebutuhan pektin untuk industri selama ini banyak diimpor dari negara China, Eropa (Jerman dan Denmark) serta Amerika. Menurut penelitian kebutuhan pektin di Indonesia meningkat dari tahun ke tahun. Pada tahun 2020 diperkirakan kebutuhan pektin mencapai 1320 ton (Puspitasari, 2017). Jumlah ini sebenarnya dapat dipenuhi apabila ada pemanfaatan dari kulit jeruk sebagai sumber produksi pektin oleh industri di Indonesia.

Fungsi pektin awalnya digunakan dalam pembuatan gel dan selai, namun saat ini meluas, banyak digunakan dalam bidang industri baik industri makanan, minuman, maupun farmasi dan kosmetik (May, 1990). Kemampuan pektin dalam membentuk gel dalam larutan encer dapat dimanfaatkan pada industri minuman sebagai pengental atau stabilizer. Food and Drug Administration/FDA menggolongkan pektin termasuk juga modifikasi pektin ke dalam golongan food additive.

Pada penelitian ini pektin jeruk bali diekstraksi menggunakan asam sitrat. Asam sitrat digunakan karena keamanannya dalam produk pangan. Pektin yang didapatkan dikarakterisasi dan diformulasikan sebagai bahan penstabil dalam pembuatan sirup kering buah mengkudu.

Buah mengkudu telah lama digunakan sebagai bahan aktif obat, makanan dan minuman oleh negara maju dengan proses produksi dan teknologi modern (Djauhariya dan Rosman, 2000). Buah mengkudu memiliki beragam aktivitas seperti antitumor (Hirazumi \& Furuzawa, 1999), antioksidative dan inflamatory (Lin et al, 2013), imunomodulator (Suhirman dan Winarti, 2010), mengurangi rasa sakit atau analgetik (Younos et al, 1990). Buah mengkudu mengandung senyawa asam kaprilat dan asam kaproat, merupakan asam lemak yang menyebabkan bau busuk tajam menyengat (Winarti, 2005). Untuk mengatasi masalah tersebut dapat digunakan bahan tambahan berupa essence atau menggunakan buah yang matang namun mengkal. Sementara untuk kepraktisan serta kemudahan dilakukan formulasi berupa sirup kering buah mengkudu. Sirup kering merupakan obat atau campuran obat dengan sakarosa, yang harus dilarutkan dahulu dalam air dalam jumlah tertentu sebelum digunakan. Formulasi sirup kering dalam penelitian ini menggunakan buah mengkudu sebagai bahan aktif dan pektin jeruk bali sebagai bahan penstabil. Bahan penstabil atau pensuspensi digunakan agar sirup kering stabil dan homogen setelah sirup digunakan (Anwar, 2012). Penelitian ini dilakukan untuk memanfaatkan pektin hasil ekstraksi dari albedo kulit jeruk bali sebagai stabilisator dalam pembuatan sirup kering buah mengkudu.

\section{METODOLOGI \\ Bahan dan Alat}

Bahan-bahan yang digunakan dalam penelitian ini adalah kulit jeruk bali, etanol $96 \%$, etanol $70 \%$, potato dextrose agar, plate count agar, aquadestilata, buah mengkudu, asam sitrat dan sakarosa.

Alat penelitian yang digunakan adalah oven (memmert), blender (Philips), timbangan (analitical balance/Scout pro), autoclaf (Tomy/SX-500), laminar airflow/LAF (Streanline vertical), tabung reaksi, pipet tetes, cawan petri, beker glass, gelas ukur, bunsen, erlenmeyer, jarum ose, pH meter, viskosimeter (Brookfield LV), Spray Dryer (TPS15).

\section{Metode \\ Ekstraksi pektin}

Ekstraksi pektin dilakukan dalam suasana asam menggunakan asam sitrat $2,5 \%$ dengan suhu $70^{\circ} \mathrm{C}$ dan waktu 90 menit. Larutan pektin disaring kemudian diendapkan dengan pelarut etanol $96 \%$. Endapan pektin disaring dicuci 3 kali dengan etanol 96\%. Pektin yang didapatkan dikeringkan dalam oven pada 
suhu $40^{\circ} \mathrm{C}$ selama 24 jam. Pembuatan serbuk kering buah mengkudu dibuat dengan metode spray drying dimana sari buah mengkudu diperoleh dari buah mengkudu matang ditambah air $(0,5 \mathrm{~kg} / \mathrm{L})$ dan diblender. Sari disaring menggunakan kain saring kemudian ditambah bahan pengisi berupa maltodekstrin 150 gram (15\%) dari total volume (1L).
Proses pengeringan serbuk menggunakan alat spray drying dilakukan pada suhu inlet $170^{\circ} \mathrm{C}$ dan suhu outlet $80^{\circ} \mathrm{C}$ serta kecepatan pompa 250. Selanjutnya dilakukan formulasi serbuk kering yang diperoleh digunakan sebagai bahan aktif sirup kering buah mengkudu seperti terlihat pada Tabel 1.

Tabel 1. Formulasi Sirup Kering (dry syrup) Buah Mengkudu

\begin{tabular}{lcccc}
\hline Bahan (gram) & Formula 1 & Formula 2 & Formula 3 & Formula 4 \\
\hline Serbuk kering buah mengkudu & 10 & 10 & 10 & 10 \\
\hline Sakarosa & 20 & 20 & 20 & 20 \\
\hline Pektin & - & $1 \%$ & $0,5 \%$ & $1,5 \%$ \\
\hline
\end{tabular}

\section{Uji terhadap sirup kering}

Uji dilakukan terhadap $\mathrm{pH}$, viskositas, endapan, mudah tidaknya terdispersi, Angka Lempeng Total (ALT) dan Angka Kapang dan Khamir (AKK).

\section{HASIL DAN PEMBAHASAN}

Ekstraksi pektin dilkukan terhadap albedo kulit jeruk bali mengingat bagian flavedo jeruk banyak mengandung kloroplas dan kelenjar minyak yang dapat mengganggu proses ekstraksi. Ekstraksi dilakukan dalam suasana asam/air asam terhadap albedo kering kulit jeruk. Penggunaan asam sitrat karena lebih aman untuk penggunaan secara oral/ konsumsi (Nurhayati dkk, 2016). Jumlah penambahan air asam akan berpengaruh terhadap proses ekstraksi karena jika kurang terbentuk pasta kental dan proses ekstraksi tidak maksimal, sementara jika terlalu encer maka memperlama proses pengeringan. Proses ekstraksi dilakukan pada suhu $70^{\circ} \mathrm{C}$ dalam waktu 90 menit.
Pektin jeruk bali yang didapatkan adalah pektin dengan bilangan ekivalensi/BE 751,17, kadar air 5,77, kadar abu 1,43, kadar metoksil 5,50\% dan rendemen $5,575 \%$. Pektin yang dihasilkan pada proses ekstraksi ini adalah jenis lowmethoxyl pektin, yaitu dibawah 7,12\%. Diatas $7,12 \%$ jenis pektin adalah highmethoxyl pektin. Pektin yang diisolasi dari kulit jeruk adalah jenis low-methoxyl pektin, sementara dari apel adalah jenis high-methoxyl pektin (Axelos \& Tibault, 1991).

\section{Pembuatan serbuk buah mengkudu}

Rendemen yang didapatkan adalah rata-rata 84,6\% dengan $\mathrm{pH} 6,39$. Rendeman sedikit lebih kecil dari berat bahan pengisi karena terdapat loss drying, kehilangan masa serbuk akibat agregasi dan penempelan yang kuat pada dinding tabung/alat. Adapun hasil uji organoleptik serbuk kering buah mengkudu seperti Tabel 2.

Tabel 2. Karakteristik Serbuk Kering Buah Mengkudu

\begin{tabular}{lllccc}
\hline \multicolumn{1}{c}{ Sampel } & \multicolumn{2}{c}{ Organoleptik } & $\begin{array}{c}\text { Kadar air } \\
(\%)\end{array}$ & $\begin{array}{c}\text { Kadar abu } \\
(\%)\end{array}$ & Kelarutan \\
\hline $\begin{array}{l}\text { Serbuk kering } \\
\text { mengkudu }\end{array}$ & buah & $\begin{array}{l}\text { Serbuk kering, putih } \\
\text { kecoklatan bau dan rasa } \\
\text { khas buah mengkudu }\end{array}$ & 4,784 & 0,738 & $91,89 \%$ \\
\hline
\end{tabular}

Organoleptik serbuk kering buah mengkudu sebagai bahan aktif formula memiliki warna putih kecoklatan dengan bau khas buah mengkudu dengan kadar air 4,784 kadar abu 0,738 serta kelarutan $91,89 \%$ atau mudah larut dalam air. 
Serbuk kering buah mengkudu memiliki khasiat dalam menstabilkan tekanan darah. Serbuk kering dibuat dari ekstrak air dengan metode spray drying karena secara tradisional senyawa aktif buah mengkudu larut dalam pelarut air dan cepat terbentuk serbuk dengan proses spray drying. Spray drying juga menggunakan maltodekstrin untuk melindungi bahan aktif dari kerusakan akibat panas/oksidasi (Purnomo dkk, 2016).

Buah mengkudu banyak memiliki manfaat kesehatan seperti mengurangi rasa sakit/analgetik, antioksidan, antiinflamasi dan penghambat xanthine oxidase. Sebagai bahan baku obat buah mengkudu digunakan dalam pengobatan diabetes, hipertensi, tukak lambung, arteriosklerosis (Wang et al, 2002).

Buah mengkudu aman dikonsumsi karena dikategorikan dalam zat yang praktis tidak toksik. LD50 buah mengkudu secara oral adalah lebih besar dari 15000 $\mathrm{mg} / \mathrm{kg}$ (West et al, 2006). Buah mengkudu diformulasikan dalam bentuk sirup kering an secara tradisional digunakan untuk menstabilkan atau menurunkan tekanan darah. Klaim ini dikarenakan adanya scopoletin yang dapat menurunkan resistensi perifer (ACE inhibitor) dan xeronine memiliki aktifitas diuretik.

\section{Uji pH dan Viskositas}

Penentuan nilai $\mathrm{pH}$ dilakukan dengan menambahkan sirup kering dengan air matang hangat ke dalam botol sampai volume $100 \mathrm{ml}$. Sirup dikocok sampai larut sempurna dan didiamkan. Selanjutnya dilakukan uji $\mathrm{pH}$ menggunakan $\mathrm{pH}$ meter. Elektroda dibilas dengan akuades sebelum digunakan. Viskositas tiap-tiap formula diukur dengan alat viskosimeter Brookfield LV dengan spindle $\mathrm{S}_{62}$. Stabilitas $\mathrm{pH}$ dan viskositas diukur selama 7 hari (FI IV, 1995) dan didapatkan nilai pada Tabel 3.

Tabel 3. Nilai pH dan Viskositas Sirup Kering Buah Mengkudu

\begin{tabular}{lcccccccc}
\hline \multirow{2}{*}{ Formula } & \multicolumn{4}{c}{$\mathrm{pH}$ hari ke- } & \multicolumn{6}{c}{ Viskositas (cps)hari ke- } \\
\cline { 2 - 9 } & 1 & 3 & 5 & 7 & 1 & 3 & 5 & 7 \\
\hline Formula 1 & 4,54 & 4,55 & 4,59 & 4,60 & 420 & 360 & 340 & 340 \\
\hline Formula 2 & 4,11 & 4,14 & 4,15 & 4,17 & 540 & 540 & 540 & 540 \\
\hline Formula 3 & 3,95 & 3,98 & 3,98 & 3,96 & 600 & 660 & 660 & 660 \\
\hline Formula 4 & 3,84 & 3,84 & 3,84 & 3,80 & 660 & 660 & 660 & 660 \\
\hline
\end{tabular}

Sirup kering tanpa pektin dalam formula 1 memiliki $\mathrm{pH}$ lebih tinggi dari formula 2, 3, dan 4 dimana $\mathrm{pH}$ menurun dengan semakin meningkatnya kadar pektin. Pektin bersifat asam sehingga menurunkan $\mathrm{pH}$ sirup kering (Indrasti dalam Mardini dkk, 2007). Pektin stabil pada $\mathrm{pH} 2-4$, diluar rentang tersebut dapat mengalami depolimerisasi (Farobie, 2006). Hal ini terlihat pada penambahan pektin dapat mempengaruhi stabilitas viskositas (Setianto dkk, 2016) seperti terlihat pada formula 2, 3 dan 4. Tanpa penambahan pektin viskositas formula 1 menurun atau tidak stabil, sementara formula 2, 3 dan 4 tetap. Penambahan pektin dalam formula sirup kering dapat mempertahankan viskositas dan $\mathrm{pH}$ selama 7 hari pengujian.

\section{Uji pengendapan}

Formula sirup kering ditambahkan air matang dalam botol sirup sampai volume $100 \mathrm{ml}$. Larutan sirup dikocok sampai homogen dan dilihat terjadinya pengendapan hari ke 1, 3, 5 dan 7 setelah rekonstitusi dan kemudahan dalam dispersinya dengan pengocokan selam 7 hari. Hasil uji dapat terlihat pada Tabel 4. 
Tabel 4. Pengendapan dan Dispersibilitas Sirup Kering

\begin{tabular}{lcccccccc}
\hline Formula & \multicolumn{4}{c}{ Endapan } & \multicolumn{4}{c}{ Mudah terdispersi } \\
\cline { 2 - 9 } & 1 & 3 & 5 & 7 & 1 & 3 & 5 & 7 \\
\hline Formula 1 & - & - & - & - & mudah & mudah & mudah & mudah \\
\hline Formula 2 & - & ada & ada & ada & mudah & mudah & mudah & mudah \\
\hline Formula 3 & - & ada & ada & ada & mudah & mudah & mudah & mudah \\
\hline Formula 4 & - & ada & ada & ada & mudah & mudah & mudah & mudah \\
\hline
\end{tabular}

Uji pengendapan terhadap formula sirup kering untuk formula tanpa penambahan pektin atau formula 1 paling baik, karena tidak terdapat endapan. Sementara untuk formula dengan pektin atau formula 2,3 dan 4 terbentuk sedikit endapan pada hari ke-3 namun mudah terdispersi kembali. Hal ini karena ada sedikit pektin yang mengendap, namun dengan pengocokan sedikit mudah terdispersi kembali. Penambahan pektin memang dapat membentuk endapan dalam penyimpanan (Ibrahim et al, 2011), namun mudah terdispersi dengan pengocokan ringan.

\section{Uji Angka Lempeng Total/ALT}

Sirup kering ditujukan untuk digunakan dalam jangka waktu selama seminggu. Setelah rekonstitusi sirup kering buah mengkudu dilakukan uji nilai angka lempeng total/ ALT diuji di laboratorium mikrobiologi untuk menentukan cemaran yang terjadi. Nilai angka lempeng total sirup kering tanpa dan dengan bahan penstabil pektin terlihat seperti Tabel 5.

Tabel 5. Nilai ALT Sirup Kering Buah Mengkudu

\begin{tabular}{lcccc}
\hline \multirow{2}{*}{ Formula } & \multicolumn{5}{c}{ ALT } & hari ke- & 7 \\
\cline { 2 - 5 } & 1 & 3 & 5 & $2,0 \times 10^{1} \mathrm{kol} / \mathrm{gr}$ \\
\hline Formula 1 & $<25 \mathrm{kol} / \mathrm{gr}$ & $<25 \mathrm{kol} / \mathrm{gr}$ & $2,0 \times 10^{1} \mathrm{kol} / \mathrm{gr}$ & $25 \mathrm{kol} / \mathrm{gr}$ \\
\hline Formula 2 & $<25 \mathrm{kol} / \mathrm{gr}$ & $<25 \mathrm{kol} / \mathrm{gr}$ & $<25 \mathrm{kol} / \mathrm{gr}$ & $<25 \mathrm{kol}$ \\
\hline Formula 3 & $<25 \mathrm{kol} / \mathrm{gr}$ & $<25 \mathrm{kol} / \mathrm{gr}$ & $<25 \mathrm{kol} / \mathrm{gr}$ & $<25 \mathrm{kol} / \mathrm{gr}$ \\
\hline Formula 4 & $<25 \mathrm{kol} / \mathrm{gr}$ & $<25 \mathrm{kol} / \mathrm{gr}$ & $<25 \mathrm{kol} / \mathrm{gr}$ & $<25 \mathrm{kol} / \mathrm{gr}$ \\
\hline
\end{tabular}

Pengujian ALT dari sirup kering pada formula 1 tanpa pektin hari ke-5 mulai ada pertumbuhan, sementara pada formula 2,3 dan 4 sampai hari ke-7 masih dibawah batas $\leq 10^{6} \mathrm{kol} / \mathrm{gr}$. Hal ini dimungkinkan bahwa pektin juga memiliki sifat antimikrobia (Espitia et al, 2014).

\section{Uji Angka Kapang dan Khamir}

Sementara nilai angka kapang dan khamir juga didapatkan hasil yang tidak jauh berbeda dengan nilai angka lempang total seperti Tabel 6, dibawah batas cemaran maksimum yaitu $\leq 10^{4} \mathrm{kol} / \mathrm{gr}$. Pertumbuhan mikrobia (ALT dan AKK) dalam uji seperti terlihat pada Tabel 6.

Tabel 6. Nilai Angka Kapang dan Khamir Sirup Buah Mengkudu

\begin{tabular}{lcccc}
\hline Formula & \multicolumn{4}{c}{ Angka Kapang Khamir hari ke- } \\
\cline { 2 - 5 } & 1 & 3 & 5 & 7 \\
\hline Formula 1 & $1,0 \times 10^{1} \mathrm{kol} / \mathrm{gr}$ & $1,0 \times 10^{1} \mathrm{kol} / \mathrm{gr}$ & $1,0 \times 10^{1} \mathrm{kol} / \mathrm{gr}$ & $1,0 \times 10^{1} \mathrm{kol} / \mathrm{gr}$ \\
\hline Formula 2 & $<10 \mathrm{kol} / \mathrm{gr}$ & $<10 \mathrm{kol} / \mathrm{gr}$ & $<10 \mathrm{kol} / \mathrm{gr}$ & $<10 \mathrm{kol} / \mathrm{gr}$ \\
\hline Formula 3 & $<10 \mathrm{kol} / \mathrm{gr}$ & $<10 \mathrm{kol} / \mathrm{gr}$ & $<10 \mathrm{kol} / \mathrm{gr}$ & $<10 \mathrm{kol} / \mathrm{gr}$ \\
\hline Formula 4 & $<10 \mathrm{kol} / \mathrm{gr}$ & $<10 \mathrm{kol} / \mathrm{gr}$ & $<10 \mathrm{kol} / \mathrm{gr}$ & $<10 \mathrm{kol} / \mathrm{gr}$ \\
\hline
\end{tabular}

Selain anti bakteri, pektin juga memiliki aktivitas anti fungi (El-Nakeeb \& Yousef, 1970). Hal ini terlihat pada uji angka kapang dan khamir dimana dari hari ke 1 formula 1 talah ada indikasi pertumbuhan kapang dan khamir sementara formula 2,3,dan 4 sampai hari ke 7 belum ada pertumbuhan atau 
dibawah nilai cemaran. Namun secara umum sirup kering buah mengkudu yang diuji selam 7 hari masih memenuhi batas mutu obat tradisional untuk batas cemaran mikroba ALT sebesar $\leq 10^{6} \mathrm{kol} / \mathrm{gr}$ dan AKK sebesar $\leq 10^{4} \mathrm{kol} / \mathrm{gr}(\mathrm{BPOM}, 2014)$.

\section{KESIMPULAN}

Jeruk bali yang diekstraksi dengan asam sitrat $2,5 \%$ pada suhu $70^{\circ} \mathrm{C}$ dan waktu 90 menit memiliki rendemen pektin sebesar 5,575\%, bilangan ekivalensi 751,17, kadar air 5,77, kadar abu 1,43, kadar metoksil 5,50\% (low methoxy) pectin).

Formula sirup kering dengan penambahan pektin $0,5 \%$ memiliki $\mathrm{pH}$ 4.57, viskositas 540 serta nilai ALT jauh dibawah batas $\leq 10^{6} \mathrm{kol} / \mathrm{gr}$ dan AKK $\leq 10^{4}$ $\mathrm{kol} / \mathrm{gr}$ untuk batas cemaran mikroba dan kapang selama 7 hari setelah waktu rekonstitusi.

\section{DAFTAR PUSTAKA}

Anwar, E., \& Antokalina, S. V., 2012, Pati Pregel Pati Singkong Fosfat Sebagai Bahan Pensuspensi

Sirup Kering Ampisilin, Pharmaceutical Sciences and Research (PSR), Vol.3 No.3 Hal : 117-126.

Axelos, M. A. V., \& Thibault, J. F., 1991, The Chemistry of low-Methoxyl Pectin Gelation, The Themistry and Technology of Pectin

Badan Pengawas Obat dan Makanan, 2014, Peratauran Kepada Badan Pengawas Obat dan Makanan Nomor 12 Tahun 2014 Tentang Persyaratan Mutu Obat Tradisional, Jakarta.

Departemen Kesehatan, 1995, Farmakope Indonesia, Edisi IV, Jakarta.

Djauhariya, E., \& Rosman, R., 2000, Status Perkembangan Teknologi Tanaman Mengkudu, Balai Penelitian Tanaman Obat dan Aromatik, Kementerian Pertanian

El-Nakeeb, M. A., \& Yousef, R. T., 1970, Study of Antimicrobial Action of Pectin. I. Antibacterial and Antifungal Activities of Pectin,
Planta medica, Vol 18 No.3 Hal : 201-209.

Espitia, P. J. P., Du, W. X., de Jesús AvenaBustillos, R., Soares, N. D. F. F., \& McHugh, T. H., 2014, Edible films from pectin: Physical-Mechanical and Antimicrobial Properties-A review, Food Hydrocolloids, Vol. 35 Hal : 287-296.

Farobie, O., 2006, Pembuatan dan Pencirian Pektin Asetat, Thesis, Institut Pertanian Bandung

Food and Drug Administration, Food Additive Status List, diakses pada http://www.fda.gov/Food/Ingredie ntsPackagingLabeling/FoodAdditiv esIngredients/ucm091048.htm 15 Februari 2017

Hirazumi, A., \& Furusawa, E., 1999, An Immunomodulatory

Polysaccharide-Rich Substance from The Fruit Juice of Morinda citrifolia(noni) with Antitumour Activity, Phytotherapy Research, Vol.13 No. $5 \mathrm{Hal}$ : 380-387

Ibrahim, G. E., Hassan, I. M., Abd-Elrashid, A. M., El-Massry, K. F., Eh-Ghorab, A. H., Manal, M. R., \& Osman, F., 2011, Effect of Clouding Agents on the Quality of Apple Juice during Storage, Food Hydrocolloids, Vol.25 No. $1 \mathrm{Hal}$ : 91-97.

Lin, Y. L., Chang, Y. Y., Yang, D. J., Tzang, B. S., \& Chen, Y. C., 2013, Beneficial Effects of Noni (Morinda citrifolia L.) Juice on Livers of High-fat Dietary Hamsters, Food Chemistry, Vol.140 No.1 Hal : 3138.

Mardini, N., Malahayati, N., \& Arafah, E., 2007, Sifat Fisik, Kimia, dan Sensoris Sari Buah Nenas dengan Penambahan Kalsium Sitrat Malat (CCM) dan Pektin, Seminar Nasional Teknologi, Yogyakarta, 24 Nopember 2007

May, C. D., 1990, Industrial Pectins: Sources, Production and Applications, Carbohydrate polymers, Vol. 12 No.1 Hal : 79-99. 
Nurhayati, N., Maryanto, M., \& Tafrikhah, R., 2016, Ekstraksi Pektin dari Kulit dan Tandan Pisang dengan Variasi Suhu dan Metode, Jurnal Agritech, Vol.36 No.03 Hal : 327334

Purnomo, W., Khasanah, L. U., \& Anandito, B. K., 2016, Pengaruh Ratio Kombinasi Maltodekstrin,

Karagenan dan Whey Terhadap Karakteristik Mikroenkapsulan Pewarna Alami Daun Jati (Tectona Grandis LF), Jurnal Aplikasi Teknologi Pangan, Vol.3 No.3 Hal : 121-129

Puspitasari, L. N., \& Puspitasari, N., 2017, Prarencana Pabrik Pektin dari Kulit Jeruk Bali Kapasitas 264 ton pektin/tahun, Disertasi, Universitas Widya Mandala, Surabaya

Setianto, Y. C., Pramono, Y. B., \& Mulyani, S., 2016, Nilai pH, Viskositas, dan Tekstur Yoghurt Drink dengan Penambahan Ekstrak Salak Pondoh (Salacca zalacca). Jurnal Aplikasi Teknologi Pangan, Vol.3No.3 Hal : 110-113

Suhirman, S., \& Winarti, C., 2010, Prospek dan Fungsi Tanaman Obat Sebagai Imunomodulator, Balai Penelitian Tanaman Obat dan Aromatik, Kementerian Pertanian

Wang, M. Y., West, B. J., Jensen, C. J., Nowicki, D., Su, C., Palu, A. K., \& Anderson, G., 2002, Morinda citrifolia (Noni): $A$ Literature
Review and Recent Advances in Noni Research. Acta Pharmacologica Sinica, Vol. 23 No. $12 \mathrm{Hal}: 1127-1141$

Wang, X., Chen, Q., \& Lü, X., 2014, Pectin Extracted from Apple Pomace and Citrus Peel by Subcritical Water, Food Hydrocolloids, Vol.38 Hal : 129-137.

West, B. J., Jensen, C. J., Westendorf, J., \& White, L. D., 2006, A Safety Review of Noni Fruit Juice, Journal of Food Science, Vol.71 No. $8 \mathrm{Hal}$ : 100-106

Willats, W. G., McCartney, L., Mackie, W., \& Knox, J. P., 2001, Pectin: Cell Biology and Prospects for Functional Analysis : Plant Molecular Biology, Vol.47 No.1 Hal : 9-27.

Winarti, C., 2005, Peluang Pengembangan Minuman Fungsional dari Buah Mengkudu (Morinda citrifolia L.), Jurnal Litbang pertanian, Vol.24 No.4 Hal : 149-155.

Yadav, S., Yadav, P. K., Yadav, D., \& Yadav, K. D. S., 2008, Purification and Characterization of an Alkaline Pectin Lyase from Aspergillus flavus. Process Biochemistry, Vol. 43 No. 5 Hal : 547-552.

Younos, C., Rolland, A., Fleurentin, J., Lanhers, M. C., Misslin, R., \& Mortier, F., 1990, Analgesic and Behavioural Effects of Morinda citrifolia, Planta Medica, Vol.56 No.05 Hal : 430-43 